\title{
Breast Cancer Perception Scale: Psychometric Development Study
}

\author{
(1) Seçil Taylan, (1) İlknur Özkan, (1) Derya Adıbelli \\ Department of Nursing, Akdeniz University, Antalya, Turkey
}

\begin{abstract}
Objective: The Breast Cancer Perception Scale was developed using a well-supported theory, thought to be associated with breast cancer prevention behaviors. The aim of this study is to develop the Breast Cancer Perception Scale based on the Health Belief Model and conduct psychometric analysis.

Materials and Methods: The study was conducted with women aged 20 or above with a methodological design. The scale study was conducted with 572 women who were not diagnosed with breast cancer and willing to participate in the study.

Results: The results of the exploratory factor analysis revealed that the scale is made up of six sub-dimensions (perceived knowledge, perceived treatment belief, the perceived need for a health check, perceived stigma, perceived fear, perceived risk) and 24 items, which explain the $74.36 \%$ of the total variance. The model obtained from the confirmatory factor analysis was within the limits of the acceptable fit index and factor loads between 0.655 and 0.998 . Cronbach's alpha reliability coefficient of the scale sub-dimensions was determined as $0.815-0.950$.

Conclusion: The overall psychometric evaluation results of the Breast Cancer Perception Scale found it to be a valid and reliable instrument that can be associated with multi-dimensional cases, such as healthy life behaviors in women, breast cancer diagnostic behaviors, family history, traumatic experiences regarding breast cancer, and the level of breast cancer knowledge.
\end{abstract}

Keywords: Breast cancer, perception, reliability, validity

Cite this article as: Taylan S, Özkan İ, Adıbelli D. Breast Cancer Perception Scale: Psychometric Development Study. Eur J Breast Health 2021; 17(2): 95-102

\section{Key Points}

- Using a well-supported theory in the study, the Breast Cancer Perception Scale was developed, which is thought to be associated with breast cancer prevention behaviors. This scale can be used to evaluate and understand the relationship between breast cancer and breast cancer diagnostic behaviors, such as breast self-examination, clinical breast examination, getting mammography, and maintaining healthful behaviors like diet, exercise, and healthy eating.

\section{Introduction}

Breast cancer is the most common cancer type with the highest mortality rate in women globally and in Turkey (1). With early diagnosis, survival and treatment increases by $90 \%$ in breast cancers (2). For cancers with genetic and environmental risk factors, measures that focus on changeable risk factors and early diagnosis are essential strategies (3, 4). Healthy People 2020 program by the United States Office of Disease Prevention and Health Promotion objectives include reducing breast cancer mortality rate, decreasing the number of people with late-stage cancer, and improving women's breast cancer diagnosis behaviors (5). It is important for these objectives to determine women's breast cancer perceptions as breast cancer perceptions and diagnosis behaviors with healthy living are considered to be significantly associated.

\section{Perceived breast cancer}

Perception is the process of evaluating her recent experiences and past experiences and reaching a new whole (6). Understanding how breast cancer perceptions affect healthy living and early diagnosis behaviors are important to increase such behaviors. This study developed Breast Cancer Perception Scale by taking The Health Belief Model as a reference.

In the literature, women's beliefs about mammography and breast self-examination (7), their perceived sensitivity to breast cancer, and their perceived benefits and barriers to mammography use (8), fear of breast cancer (9), fatalism toward cancer (10), and their attitude toward cancer have 
scales that evaluate them separately (11). With the developed Breast Cancer Perception Scale, women's perceptions of the factors affecting breast cancer diagnosis behavior are evaluated as a whole. This scale is complementary. In addition, the perceived knowledge sub-dimension of the Breast Cancer Perception Scale has not been measured before, according to the authors' knowledge, and it is a unique scale that measures a person's breast cancer knowledge perception. The Health Belief Model is commonly used to explain breast cancer diagnosis behaviors (11-14). Therefore, this scale development study was based on the Health Belief Model. The Health Belief Model was developed by Becker and his colleagues (1974) to understand protective behaviors regarding health. It argues that people's healthcare behaviors can be affected by beliefs, values, and attitudes. According to the Model, if the beliefs and attitudes seen as problems are identified, healthcare training or offered treatment can be customized as more effective for that person $(7,8,15)$. Women's breast cancer perceptions may affect their breast cancer diagnosis behavior. For this reason, it is essential to measure women's breast cancer perceptions multidimensionally. The aim of this study is to develop a Breast Cancer Perception Scale with reference to the Health Belief Model and evaluate it psychometrically.

\section{Materials and Methods}

This study is a methodological study conducted with women aged 20 and over in a district in the south of Turkey without a breast cancer diagnosis. For a psychometric analysis in a development study using a scale, it is recommended that the sample be between 10 and 20 times the number of items on the scale $(16,17)$. Considering the number of items, the study was completed with 572 women. The study inclusion criteria were literate, women over the age of 20, no cancer diagnosis, no communication impairment (hearing and speech), no disability to answer questions physically, cognitively, or mentally, and agreed to participate in the study. Study data were collected by the face-to-face interview method between September 2019 and March 2020. The questionnaires took approximately 10-15 minutes to answer.

\section{Data collection forms}

\section{Descriptive characteristics form}

The form consists of questions prepared by the researchers involving information on the age, education, marital status, employment status, income level, and socio-demographic characteristics. The form also includes questions regarding family history of breast cancer, regular breast self-examination, routine clinical breast examination, and routine mammography for women above 40 .

\section{Breast cancer perception scale}

First, a comprehensive literature review was conducted to develop the Breast Cancer Perception Scale. The draft scale, which was initially developed with 35 items, has a 5-point Likert-type structure with responses varying between "Strongly Agree" (5) and "Strongly Disagree" (1). Some scales available in the literature were used as references to ensure the scale items' construct and criteria validity. These scales measure beliefs on breast mammography and breast selfexamination (7), perceived sensitivity regarding breast cancer and perceived benefits and obstacles to mammography (8), fear of breast cancer (9), fatalism regarding cancer (10), and attitudes toward cancer (11). The formulated items were reviewed by 10 breast cancer experts. The experts reviewed all factors relevant to conceptual perception regarding breast cancer and suggested some editorial changes. Finally, resulted in the 24-item version. The sub-dimensions of the scale are explained below.

\section{Perceived knowledge}

Perceived knowledge includes prejudices such as hidden selfconfidence and unrealistic optimism (18). The perceived knowledge sub-dimension is not related to a person's knowledge level on breast cancer. It is related to how knowledgeable a person sees herself. It arouses curiosity on how a person's high perceived knowledge on breast cancer influences preventive breast cancer behaviors.

\section{Perceived treatment belief}

Perceived treatment belief can be influenced by women's spiritual and religious beliefs, previous breast cancer treatment experiences, and family breast cancer treatment stories. The studies on spirituality and health screening behavior present inconsistent findings (19-21). In this regard, a person's perceived treatment belief can affect her protective behaviors.

\section{Perceived need for health check}

Having a low perceived need for a health check is one of the primary obstacles in breast cancer screening practices among women. Women do not feel the need to go to a doctor unless they know disease signs and symptoms $(22,23)$. Studies showed that women in developing countries are inclined to reject the concept of early diagnosis saves lives because of their beliefs regarding having breast cancer. This has a negative effect on taking preventive measures regarding cancer (2326). Low or high scores on the perceived need for health check may influence breast cancer protective behaviors.

\section{Perceived stigma}

The breast has a symbolic meaning that differs from other organs, as it is associated with giving birth, raising a child, and sexuality (27). This symbolic meaning can become an obstacle for women in the care, treatment, or screenings related to their breasts $(27,28)$. Silence regarding breast cancer and screening behaviors can be associated with the taboo perceptions about breasts (29).

\section{Perceived fear}

The level of perceived fear can impact women's breast cancer protective behavior. Studies point out that women experience fear of receiving a breast cancer diagnosis and losing one or both breasts $(5,30-32)$. Similarly, another study revealed that women with high breast cancer fear get fewer mammographies in 12 months (33).

\section{Perceived risk}

Perceived risk is an important factor affecting breast cancer protective behavior (5, 30-32). Witnessing their loved ones difficulties and pain during the breast cancer process increases perceived breast cancer fear and perceived breast cancer risk $(34,35)$. In their study, Whitney et al. (36) reported that women with high perceived risk also have a higher perceived risk for breast cancer.

\section{Psychometric tests used}

\section{Validity}

Exploratory (EFA) and confirmatory factor analysis (CFA) methods were used to determine the scale's construct validity. Before EFA, Bartlett's Test for Sphericity and Keiser-Mayer-Olkin (KMO) tests were implemented to examine the scale's content and sample size adequacy. For the sample size to be adequate for factor analysis, KMO has to 
be above 0.60 , and Bartlett's test for Sphericity has to be statistically significant $(16,17)$. Moreover, for construct validity, EFA and Direct Oblimin analysis was implemented to associated group items in a particular set (16). Following EFA, CFA was implemented to support the findings of the scale. The Goodness of Fit Indices of the model were analyzed after CFA; $\mathrm{x}^{2} /$ standard deviation $(\mathrm{SD})$ rate $\leq 5$; root mean square error of approximation (RMSEA) $\leq 0.08$; and Goodness of Fit Index (GFI), Comparative Fit Index (CFI), and Incremental Fit Index (IFI) values of above 0.90 indicates that the model is within acceptable goodness of fit limits $(16,17,37,38)$.

\section{Reliability}

The sub-dimension item-total score correlation coefficients and Cronbach's alpha values as the internal consistency analysis for the items in the scale were calculated to determine the reliability of the adapted scale. The time invariance of the scale was assessed through the test-retest technique applied three weeks after the first implementation with 30 participants. Pearson Product-Moment Correlation Coefficient was implemented for the test-re-test method.

\section{Statistical analysis}

The data collected from the study were analyzed through Statistical Package for the Social Sciences (SPSS) 23.0 for Windows software (SPSS Inc, Chicago, Illinois) and Analysis of Moment Structures (AMOS) 24.0. Descriptive statistics such as percentage, frequency, minimum-maximum values, mean, and standard deviation were used to analyze socio-demographic data. EFA and CFA techniques were implemented for the construct validity of the scale. The direct Oblimin method was used in the EFA. Bartlett's test for Sphericity and KMO tests were implemented for the scale content and sample size adequacy. CFA was used to examine the factor construct and factor loads of the scale. A t-test and Pearson product-moment correlation tests were implemented to determine the relationship between the repeat measurements. The significance level was accepted as 0.05 .

\section{Ethical approval}

The ethical considerations of the study were evaluated by the Akdeniz University Clinical Studies Ethics Board, and ethical approval was received (number of meetings: 78; decision number: 727; date of decision: 24.07.2019). Patients in the sample were informed about the study, and their written consent was also received for the study.

\section{Results}

\section{Descriptive characteristics of patients}

In the study involving 572 women; It was found that the mean age of the women who participated in the study was $45.79 \pm 14.85,33.7 \%$ was aged $20-29,28.1 \%$ was elementary school graduate, $71.2 \%$ was married, $43.2 \%$ was housewife, and $55.9 \%$ perceived their income and expense levels as equal. Of all participating women, $50.9 \%$ sometimes conducted breast self-examination, $68.0 \%$ never had clinical breast self-examination, $40.8 \%$ of the women aged above 40 never had mammography, and $84.4 \%$ were found to have a family history of breast cancer (Table 1).

\section{Content validity}

The formed scale was sent to 10 expert faculty members (three public health nursing, one internal medicine nursing, two surgical nursing, and three psychiatric nursing). Davis' technique was used for content validity. The content validity index values of the draft scale were found to be 0.93 on average and varied between 0.60 and 1.00. Upon evaluating the comments from the experts, the scale was implemented to 30 women. These 30 women participants were not included in the study. Each item was found evident in the pre-implementation stage, so no changes were deemed necessary for the scale.

\section{Psychometric test results \\ Validity}

Before factor analysis, the KMO sampling adequacy test and Bartlett's test for Sphericity were implemented to determine whether the sample was adequate and the factor correlation matrix was good for fit. KMO value was found as 0.770 , and Bartlett's test for Sphericity result was determined as $\mathrm{x}^{2}=9,231.271(\mathrm{p}=0.000)$.

First, EFA was conducted to determine the number of sub-scales. The analysis showed that the scale has a 6-factor construct with a self-value above 1.00. The direct Oblimin Method was preferred for factor analysis implementation to keep the relationship between factors stable. The variance explanation rate was $74.36 \%$. As a result of EFA, 11 items from the 35-item breast cancer detection scale items were excluded from the scale because the factor load was less than 0.30 . The scale sub-dimensions were found and named Perceived Knowledge, Perceived Treatment Belief, Perceived Need for Health Check, Perceived Stigma, Perceived Fear, and Perceived Risk. According to EFA, the scale's item factor loads vary between 0.621 and 0.952 (Table 2).

CFA was conducted to evaluate the construct validity of the Breast Cancer Perception Scale. The model was within the good fit limits as the RMSEA value was 0.072 ; chi-square value was statistically significant $\left(\chi^{2}=830.577 ; \mathrm{n}=572, \mathrm{SD}=210 \mathrm{p}=0.00\right), \chi^{2} / \mathrm{SD}=$ $830.577 / 210=3.954$; CFI value was 0.933; GFI value was 0.913, Bentler-Bonett Normed Fit Index (NFI) value was 0.901 and RMSEA value was 0.072 . The CFA results of the items in the scale showed that the factor loads varied between 0.655 and 0.998 .

\section{Reliability}

The scale consists of 24 items. High scores from the sub-dimensions indicate an increased perception regarding the relevant sub-dimension. There is the total score for the scale, and items 7, 9, 10, 11, 12, and 13 are reversely coded. The item-sub-dimension total correlation coefficients resulted from the reliability analysis and varied between 0.670 and 0.956 (Table 2).

Cronbach's alpha as the internal consistency was calculated to measure the reliability of the scale. Cronbach's alpha coefficients of the scale's sub-dimensions varied between 0.815 and 0.950 (Table 3).

The difference between the scores collected from two measurements of the draft scale repeated with a 3-week interval was analyzed through a t-test with dependent groups. The difference between the two implementations of all sub-dimensions was not statistically significant. Pearson's product-moment correlation coefficient analysis showing the consistency between the test-retest score averages of the scale showed a statistically significant, positive, and strong relationship (0.946-0.994) between the two scale sub-dimension measurements (Table 4).

\section{Discussion and Conclusion}

This study presents preliminary evidence that breast cancer perception, as a construct, can be measured in a valid and reliable way. The Breast 
Cancer Perception Scale, which is thought to be associated with breast cancer protective behaviors, was developed in the study using a wellsupported theory. There are scales in the literature that measure the beliefs on mammography and breast self-examination (7), perceived sensitivity toward breast cancer, and perceived benefits and obstacles of using mammography (8), fear of breast cancer (9), fatalism regarding cancer (10), and attitudes toward cancer (11). Although, according to the Health Belief Model, obstacles to cancer screening have been measured before. This scale enables more subjective measurements with the perceived need for health check, perceived stigma, perceived fear, and perceived risk sub-dimensions. The item pool was created by reviewing the relevant literature (7-11). As suggested by the literature, the items of the scale were finalized following expert opinions, the pilot study, and factor analyses $(16,17)$.

KMO coefficient and Bartlett's test for Sphericity tests are used to assess the goodness of fit in terms of the scale's construct validity (16, $17,39)$. When the KMO value is above 0.50 , it shows that the factor analysis can be implemented. KMO value of above 0.60 and close to
1 indicates that the data is suitable for factor analysis; KMO value between 0.70 and 0.80 indicates average; between 0.80 and 0.90 shows good; and above 0.90 indicates perfect sample adequacy (40). In the case of Bartlett's test for Sphericity being significant, the correlation matrices of the scale items are suitable for factor analysis $(16,39)$. In this study, the KMO value was 0.770 , and Bartlett's Test for Sphericity was significant $(p=0.000)$. These results indicate that the study's sample size is adequate for factor analysis, and factor analysis for the scale can be implemented.

Factor load values for the scale items must be minimum of 0.30 , and items with a value lower than this need to be omitted from the scale $(17,37,38)$. As a result of the EFA, 11 items from the 33-item Breast Cancer Perception Scale were removed. Their factor load values were below 0.30 , and the remaining 24 items were categorized under five sub-dimensions. While interpreting the EFA results, it is expected to explain a minimum of $30 \%$ of the variance in single-factor scales and $50 \%$ of the variance in multi-factor scales (41). It was seen in this study that $74.360 \%$ of the variance in the scale is explained (Table 2).

Table 1. Distribution of characteristics and behaviors to diagnose breast cancer

\begin{tabular}{|c|c|c|c|}
\hline & & n & $\%$ \\
\hline \multirow{5}{*}{$\begin{array}{l}\text { Age } \\
(45.79 \pm 14.85)\end{array}$} & 20-29 age & 193 & 33.7 \\
\hline & 30-39 age & 144 & 25.2 \\
\hline & $40-49$ age & 102 & 17.8 \\
\hline & 50-59 age & 82 & 14.4 \\
\hline & $60-69$ age & 51 & 8.9 \\
\hline \multirow{5}{*}{ Education } & Literate & 51 & 8.9 \\
\hline & Primary school & 161 & 28.1 \\
\hline & Secondary school & 122 & 21.3 \\
\hline & High school & 106 & 18.5 \\
\hline & University & 132 & 23.1 \\
\hline \multirow{4}{*}{ Marital status } & Married & 407 & 71.2 \\
\hline & Single & 165 & 28.8 \\
\hline & Homemaker & 247 & 43.2 \\
\hline & Farmer & 151 & 26.4 \\
\hline \multirow{3}{*}{ Occupation } & Public official & 111 & 19.4 \\
\hline & Worker & 21 & 3.7 \\
\hline & Self employed & 6 & 1.0 \\
\hline \multirow{4}{*}{ Economic status } & Retired & 36 & 6.3 \\
\hline & Income < expenditure & 191 & 33.4 \\
\hline & Income = expenditure & 320 & 55.9 \\
\hline & Income > expenditure & 61 & 10.7 \\
\hline \multirow{3}{*}{ Breast self-examination } & Never & 224 & 39.1 \\
\hline & Sometimes & 291 & 50.9 \\
\hline & Always regular & 57 & 10.0 \\
\hline \multirow{3}{*}{ Clinical breast examination } & Never & 389 & 68.0 \\
\hline & Sometimes & 129 & 22.6 \\
\hline & Always regular & 54 & 9.4 \\
\hline \multirow{3}{*}{$\begin{array}{l}\text { Mammography (over } 40 \text { age) } \\
\text { ( } n=235)\end{array}$} & Never & 96 & 40.8 \\
\hline & Sometimes & 88 & 37.5 \\
\hline & Always regular & 51 & 21.7 \\
\hline \multirow{2}{*}{ Familial history of breast cancer } & Yes & 89 & 15.6 \\
\hline & No & 483 & 84.4 \\
\hline
\end{tabular}


In the CFA implemented at the last step of validity analysis, the factor loads of the scale and scale consistency values were examined. CFA confirmed the construct of six sub-dimensions resulting from the EFA. According to the CFA, the factor loads of the items in the scale ranged between 0.655 and 0.998 .
While interpreting the goodness of fit values of the model, it was found to be within the goodness of fit limits as the RMSEA value was 0.072; chi-square was statistically significant $\left(\chi^{2}=830.577 ; \mathrm{n}=572\right.$; $\mathrm{SD}=210 ; \mathrm{p}=0.00)$ and $\left(\chi^{2} / \mathrm{SD}=3,043.701 / 934=3.259\right)$; CFI value was 0.933 and GFI value was 0.913 and NFI value was 0.901 . The

Table 2. Item total correlation values, reliability coefficients, and exploratory factor analysis values

\section{Item Items}

no

\section{Perceived knowledge}

1 My knowledge of breast cancer treatment is sufficient

2 I think that I have sufficient knowledge of breast cancer

3 I know what women who had breast cancer treatment should pay attention to

$4 \quad$ I know how to be protected from breast cancer

\section{Perceived treatment belief}

5 It is important for early diagnosis and treatment to attend screenings regularly

6 Early diagnosis of breast cancer increases the chances of recovery

7 Breast cancer is a treatable disease Breast self-examination is important for early diagnosis and treatment

9 Breast cancer treatment does not change the outcome

\section{Perceived need for health check}

10 I do not go to the doctor unless there is a disease finding

11 I forget to get a regular breast examination

12 It does not come to my mind to go to a regular breast examination

13 I am reluctant to be examined by a male doctor

\section{Perceived stigma}

14 Women with breast cancer experience problems in their sexual lives

15 Women with breast cancer cannot take care of their children

Women with breast cancer experience problems in their marriages

17 Breast cancer treatment makes a woman less beautiful

\section{Perceived fear}

18 It scares me to think of breast cancer

19 I feel uncomfortable when I think of breast cancer It makes me feel uneasy to think about the breast cancer treatment process

21 The thought of having breast cancer worries me

\section{Perceived risk}

22 I see myself under the risk for breast cancer

$2.81 \pm 1.11$

$2.83 \pm 1.13$

$2.79 \pm 1.14$

$2.89 \pm 1.19$

Factor

loading

0.902

variance

0.887

0.877

0.831

$3.88 \pm 1.18$

$-0.848$

$3.84 \pm 1.14$

$3.58 \pm 1.18$

$-0.840$

$-0.822$

$4.10 \pm 1.16$

$-0.786$

$4.06 \pm 1.10$

$-0.621$

$3.33 \pm 1.09$

$-0.952$

$3.40 \pm 1.08$

$3.44 \pm 1.05$

$3.27 \pm 1.07$

$2.56 \pm 1.13$

$-0.869$

$2.44 \pm 1.12$

$-0.839$

$2.68 \pm 1.17$

$-0.795$

$2.56 \pm 1.27$

$-0.688$

$3.40 \pm 1.18$

$-0.909$

$3.31 \pm 1.31$

$-0.873$

$3.21 \pm 1.25$

$-0.854$

$3.17 \pm 1.33$

$-0.780$

$3.10 \pm 1.12$

0.912

$3.22 \pm 1.08$ The risk for breast cancer
history of breast cancer

$2.98 \pm 1.15$

0.850

0.848
$\%$ of

Cumulative

$\%$

r

0.909

$19,353 \quad 19,353$

0.871

0.875

0.854

0.843

0.837

$14,685 \quad 34,039$

0.823

0.773

0.670

0.954

0.956

$13,482 \quad 47,521$

0.901

0.920

0.850

0.831

0.797

0.738

0.892

0.866

$7,794 \quad 67,054$

0.860

0.824

0.925

7,306

74,360

0.853

0.850

SD: Standard deviation; r: Sub-dimension item-sub-dimension total correlation 
Table 3. Scale subscale scores and Cronbach's alpha values

\begin{tabular}{lcc} 
& Cronbach's alpha & Mean \pm SD (min-max) \\
\hline Perceived knowledge & 0.900 & $2.82 \pm 1.00(1-5)$ \\
Perceived treatment belief & 0.850 & $3.89 \pm 0.91(1-5)$ \\
Perceived need for health check & 0.950 & $3.36 \pm 1.00(1-5)$ \\
Perceived stigma & 0.815 & $2.56 \pm 0.96(1-5)$ \\
Perceived fear & 0.896 & $3.27 \pm 1.09(1-5)$ \\
Perceived risk & 0.848 & $3.10 \pm 0.98(1-5)$ \\
\hline SD: Standard deviation; min: Minimum; max: Maximum & &
\end{tabular}

Table 4. Test-retest analysis of the scale

\begin{tabular}{|c|c|c|c|c|c|c|}
\hline & Items & $\mathbf{n}$ & $\begin{array}{c}\text { Test } \\
\text { Mean } \pm S D \\
\text { (min-max) }\end{array}$ & $\begin{array}{c}\text { Re-test } \\
\text { Mean } \pm S D \\
\text { (min-max) }\end{array}$ & $\begin{array}{c}\text { t-test } \\
p\end{array}$ & $\begin{array}{l}\mathbf{r} \\
\mathbf{p}\end{array}$ \\
\hline Perceived knowledge & 4 & 30 & $2.66 \pm 1.09$ & $2.53 \pm 1.19$ & $\begin{array}{c}-1.112 \\
0.331\end{array}$ & $\begin{array}{l}0.958 \\
0.000\end{array}$ \\
\hline Perceived treatment belief & 5 & 30 & $4.03 \pm 0.98$ & $3.97 \pm 0.93$ & $\begin{array}{l}-0.795 \\
0.432\end{array}$ & $\begin{array}{l}0.946 \\
0.000\end{array}$ \\
\hline $\begin{array}{l}\text { Perceived need for health } \\
\text { check }\end{array}$ & 4 & 30 & $3.12 \pm 41.17$ & $3.09 \pm 1.75$ & $\begin{array}{l}-0.571 \\
0.573\end{array}$ & $\begin{array}{l}0.994 \\
0.000\end{array}$ \\
\hline Perceived stigma & 4 & 30 & $2.40 \pm 0.80$ & $2.41 \pm 0.82$ & $\begin{array}{l}0.558 \\
0.592\end{array}$ & $\begin{array}{l}0.957 \\
0.000\end{array}$ \\
\hline Perceived fear & 4 & 30 & $3.40 \pm 1.30$ & $3.46 \pm 1.31$ & $\begin{array}{l}1.439 \\
0.161\end{array}$ & $\begin{array}{l}0.981 \\
0.000\end{array}$ \\
\hline Perceived risk & 3 & 30 & $3.04 \pm 0.981$ & $3.01 \pm 0.963$ & $\begin{array}{c}-1.278 \\
0.211\end{array}$ & $\begin{array}{l}0.982 \\
0.000\end{array}$ \\
\hline
\end{tabular}

t-test: Paired Sample t-Test; r: Correlation between two measurements; n: Number; min: Minimum; max: Maximum; SD: Standard deviation

literature indicates that $\mathrm{x}^{2} / \mathrm{SD}$ rate $\leq 5$; RMSEA $\leq 0.08$; and GFI, CFI, and IFI values above 0.90 shows that a model is within the acceptable fitness limits $(16,17,37,38)$.

As a result of the reliability analysis, it was determined that the itemsub-dimension total correlation coefficients ranged between 0.670 and 0.956 (Table 2). The lowest rate for item-total score correlation coefficient was considered as 0.20 . The items with a correlation coefficient between $0.30-0.40$ are reported as "good," and items above 0.40 are "very good" $(17,39)$.

Cronbach's alpha as the internal consistency coefficient was calculated to determine the scale's reliability value. Cronbach's alpha coefficients of the sub-dimensions varied between 0.815 and 0.950 . It is reported that Cronbach's alpha coefficient may vary between $0.0-1.0$; a coefficient between 0.60 and 0.80 represents a reliable scale; a value of 0.80 and above represents a highly reliable scale (16). In this regard, Cronbach's alpha values found in our study are consistent with the highly reliable values reported in the literature.

Another reliability test is the investigation of test-retest scores of the scale $(16,39)$. With this test, the correlation coefficients collected from two measurements taken at certain time intervals are examined and high correlation represents the consistency of test scores and the little variance over time between the two measurements (16). The correlation coefficients between the test-retest sub-dimension scores (0.9460.994 ) were very high (Table 3 ). These findings showed that the scale is a consistent instrument against time and has time consistency.

There are certain limitations to be considered when evaluating these study results. The study's limitations are that it was conducted in a single region, and the correlation was not conducted with similar scales.

It is important to know and measure how breast cancer is perceived by women in developing breast cancer preventive behaviors. This study, which was conducted based on The Health Belief Model, found unique characteristics regarding how breast cancer is perceived by women. This scale can be used to evaluate and understand the relationship between breast cancer and breast cancer diagnostic behaviors, such as breast self-examination, clinical breast examination, getting mammography, and maintaining healthful behaviors like diet, exercise, and healthy eating. The Breast Cancer Perception Scale is also a valid and reliable instrument to be used in relational studies on breast cancer knowledge and familial history. 
Ethics Committee Approval: The ethical considerations of the study were evaluated by the Akdeniz University Clinical Studies Ethics Board, and ethical approval was received (number of meetings: 78; decision number: 727; date of decision: 24.07.2019).

Informed Consent: Patients in the sample were informed about the study, and their written consent was also received for the study.

\section{Authorship Contributions}

Concept: S.T., İ.Ö., D.A.; Design: S.T., İ.Ö., D.A.; Data Collection or Processing: S.T., İ.Ö., D.A.; Analysis or Interpretation: S.T., İ.Ö., D.A.; Literature Search: S.T., İ.Ö., D.A.; Writing: S.T., İ.Ö., D.A.

Conflict of Interest: No conflict of interest declared by the authors.

Financial Disclosure: This research did not receive any specific grant from funding agencies in the public, commercial, or not-for-profit sectors.

\section{References}

1. Bray F, Ferlay J, Soerjomataram I, Siegel RL, Torre LA, Jemal A. Global cancer statistics 2018: GLOBOCAN estimates of incidence and mortality worldwide for 36 cancers in 185 countries. CA Cancer J Clin 2018; 68: 394-424. (PMID: 30207593) [CrossRef]

2. Griva F, Anagnostopoulos F, Madoglou S. Mammography screening and the theory of planned behavior: suggestions toward an extended model of prediction. Women Health 2009; 49: 662-681. (PMID: 20183107) [CrossRef]

3. Bertoni N, de Souza MC, Crocamo S, Szklo M, de Almeida LM. Is a family history of the breast cancer related to women's cancer prevention behaviors? Int J Behav Med 2019; 26: 85-90. (PMID: 30088188) [CrossRef]

4. Kolak A, Kaminska M, Sygit K, Budny A, Surdyka D, Kukielka-Budny B, et al. Primary and secondary prevention of breast cancer. Ann Agric Environ Med 2017; 24: 549-553. (PMID: 29284222) [CrossRef]

5. Kardan-Souraki M, Moosazadeh M, Khani S, Hamzehgardeshi Z. Factors related to breast cancer screening in women in the northern part of Iran: A cross-sectional study. Open Access Maced J Med Sci 2019; 7: 637-642. (PMID: 30894928) [CrossRef]

6. Tunç A, Atılgan A. An administrative understanding on perception: Perception administration. IDEA Studies 2017; 3: 228-238. [CrossRef]

7. Champion VL, Scott CR. Reliability and validity of breast cancer screening belief scales in African American women. Nurs Res 1997; 46: 331-337. (PMID: 24831044) [CrossRef]

8. Champion VL. Revised susceptibility, benefits, and barriers scale for mammography screening. Res Nurs Health 1999; 22: 341-348. (PMID: 10435551) [CrossRef]

9. Champion VL, Skinner CS, Menon U, Rawl S, Giesler RB, Monahan P, et al. A breast cancer fear scale: psychometric development. J Health Psychol 2004; 9: 753-762. (PMID: 15367754) [CrossRef]

10. Powe BD. Cancer fatalism among elderly Caucasians and African Americans. Oncol Nurs Forum 1995; 22: 1355-1359. (PMID: 8539176) [CrossRef]

11. Cho J, Choi EK, Kim SY, Shin DW, Cho BL, Kim CH, et al. Association between cancer stigma and depression among cancer survivors: A nationwide survey in Korea. Psychooncology 2013; 22: 2372-2378. (PMID: 23784964) [CrossRef]

12. Che Mohamed N, Moey SF, Lim BC. Validity and reliability of health belief model questionnaire for promoting breast self-examination and screening mammogram for early cancer detection. Asian Pac J Cancer Prev 2019; 20: 2865-2873. (PMID: 31554389) [CrossRef]
13. Kirag N, Kizilkaya M. Application of the champion health belief model to determine beliefs and behaviors of Turkish women academicians regarding breast cancer screening: A cross sectional descriptive study. BMC Womens Health 2019; 19: 132. (PMID: 31694619) [CrossRef]

14. Wang X, Chen D, Xie T, Zhang W. Predicting women's intentions to screen for breast cancer based on the health belief model and the theory of planned behavior. J Obstet Gynaecol Res 2019; 45: 2440-2451. (PMID: 31475426) [CrossRef]

15. Fouladi N, Pourfarzi F, Mazaheri E, Asl HA, Rezaie M, Amani F, et al. Beliefs and behaviors of breast cancer screening in women referring to health care centers in northwest Iran according to the champion health belief model scale. Asian Pac J Cancer Prev 2013; 14: 6857-6862. (PMID: 24377617) [CrossRef]

16. Büyüköztürk $S$. Data analysis handbook for social science. Original work published in Turkish. 24th ed. Ankara, Turkey: Pegem Akademi Publishing; 2018. [CrossRef]

17. Çapik C. Use of confirmatory factor analysis in validity and reliability studies. J Anatol Nursing Health Sci 2014; 17: 196-205. [CrossRef]

18. Pohl PF. Cognitive illusions: a handbook on fallacies and biases in thinking, judgement and memory. Hove, UK: Psychology Press: 2004. [CrossRef]

19. Al-Amoudi S, Canas J, Hohl SD, Distelhorst SR, Thompson B. Breaking the silence: breast cancer knowledge and beliefs among Somali Muslim women in Seattle, Washington. Health Care Women Int 2015; 36: 608616. (PMID: 24351062) [CrossRef]

20. Haji-Mahmoodi M, Montazeri A, Jarvandi S, Ebrahimi M, Haghighat S, Harirchi I. Breast self-examination: knowledge, attitudes, and practices among female health care workers in Tehran, Iran. Breast J 2002; 8: 222 225. (PMID: 1200114) [CrossRef]

21. Li CI, Malone KE, Daling JR. Differences in breast cancer stage, treatment, and survival by race and ethnicity. Arch Intern Med 2003; 163: 49-56. (PMID: 12523916) [CrossRef]

22. Kwok C, Endrawes G, Lee CF. Cultural beliefs and attitudes about breast cancer and screening practices among Arabic women in Australia. Cancer Nurs 2016; 39: 367-374. (PMID: 26645110) [CrossRef]

23. Mamdouh HM, El-Mansy H, Kharboush IF, Ismail HM, Tawfik MM, El-Baky MA, et al. Barriers to breast cancer screening among a sample of Egyptian females. J Family Community Med 2014; 21: 119-124. (PMID: 24987281) [CrossRef]

24. Kawar LN. Jordanian and Palestinian immigrant women's knowledge, affect, cultural attitudes, health habits, and participation in breast cancer screening. Health Care Women Int 2009; 30: 768-782. (PMID: 19657816) [CrossRef]

25. Donnelly TT, Al Khater AH, Al-Bader SB, Al Kuwari MG, Al-Meer N, Malik M, et al. Beliefs and attitudes about breast cancer and screening practices among Arab women living in Qatar: a cross-sectional study. BMC Womens Health 2013; 13: 49. (PMID: 24330708) [CrossRef]

26. Donnelly TT, Khater AH, Al-Bader SB, Al Kuwari MG, Al-Meer N, Malik M, et al. Arab women's breast cancer screening practices: a literature review. Asian Pac J Cancer Prev 2013; 14: 4519-4128. (PMID: 24083695) [CrossRef]

27. Banning M, Hafeez H. A two-center study of Muslim women's views of breast cancer and breast health practices in Pakistan and the UK. J Cancer Educ 2010; 25: 349-353. (PMID: 20146040) [CrossRef]

28. Banning M, Hassan M, Faisal S, Hafeez H. Cultural interrelationships and the lived experience of Pakistani breast cancer patients. Eur J Oncol Nurs 2010; 14: 304-309. (PMID: 20584625) [CrossRef]

29. Sheppard VB, Christopher J, Nwabukwu I. Breaking the silence barrier: opportunities to address breast cancer in African-born women. J Natl Med Assoc 2010; 102: 461-468. (PMID: 20575210) [CrossRef] 
30. George TO, Allo TA, Amoo EO, Olonade O. Knowledge and attitudes about breast cancer among Women: a wake-up call in Nigeria. Open Access Maced J Med Sci 2019; 7: 1700-1705. (PMID: 31210826) [CrossRef]

31. Rosner BA, Colditz GA, Hankinson SE, Sullivan-Halley J, Lacey JV Jr, Bernstein L. Validation of Rosner-Colditz breast cancer incidence model using an independent data set, the California Teachers Study. Breast Cancer Res Treat 2013; 142: 187-202. (PMID: 24158759) [CrossRef]

32. Sohbet R, Karasu F. Investigation of the knowledge, behavior and applications of their women towards breast cancer. Gümüşhane Univ J Health Sci 2017; 6: 113-121. (PMID: 27409075) [CrossRef]

33. Schwartz MD, Taylor KL, Willard KS. Prospective association between distress and mammography utilization among women with a family history of breast cancer. J Behav Med 2003; 26: 105-117. (PMID: 12776381) [CrossRef]

34. Hashemi-Ghasemabadi M, Taleghani F, Kohan S, Yousefy A. Living under a cloud of threat: the experience of Iranian female caregivers with a first-degree relative with breast cancer. Psychooncology 2017; 26: 625631. (PMID: 27328629) [CrossRef]

35. Raveis VH, Pretter S. Existential plight of adult daughters following their mother's breast cancer diagnosis. Psychooncology 2005; 14: 49-60. (PMID: 15386788) [CrossRef]
36. Whitney CA, Dorfman CS, Shelby RA, Keefe FJ, Gandhi V, Somers TJ. Reminders of cancer risk and pain catastrophizing: relationships with cancer worry and perceived risk in women with a first-degree relative with breast cancer. Fam Cancer 2019; 18: 9-18. (PMID: 29679190) [CrossRef]

37. Bayram N. Yapısal eşitlik modellemesine giriş amos uygulamaları. [Introduction to structural equation modeling] Bursa: Ezgi Kitabevi. 2016. [CrossRef]

38. Gürbüz S. AMOS ile Yapısal Eşitlik Modellemesi. Ankara: Seçkin Yayıncilık; 2019. [CrossRef]

39. Arafat SY, Chowdhury HR, Qusar M, Hafez M. Cross cultural adaptation \& psychometric validation of research instruments: A methodological review. J Behav Health 2016; 5:129-136. (PMID: 20874835) [CrossRef]

40. Tavşancıl E. Tutumların ölçülmesi ve SPSS ile veri analizi [Measurement of attitudes and data analysis with SPSS]. Ankara, Turkey: Nobel. 2006.

41. Kalaycı Ş. SPSS uygulamalı çok değişkenli istatistik teknikleri, Ankara: Asil Yayın Dağıtım Ltd. Şti; 2009. [CrossRef] 